\title{
Automatic detection of complex archaeological grazing structures using airborne laser scanning data
}

\author{
Jean-Pierre TOUMAZET ${ }^{\mathrm{a}, \mathrm{b}}$, Franck VAUTIER ${ }^{\mathrm{c}, \mathrm{d}}$, Erwan ROUSSEL ${ }^{\mathrm{a}, \mathrm{b}}$, \\ Bertrand DOUSTEYSSIER ${ }^{\mathrm{c}, \mathrm{d}}$ \\ (a) CNRS, UMR 6042, GEOLAB, F-63057 CLERMONT-FERRAND, FRANCE \\ (b) Clermont Université, Université Blaise Pascal, GEOLAB, BP 10448, F-63000 CLERMONT-FERRAND, France \\ (c) CNRS, USR 3550, MSH, F-63057 CLERMONT-FERRAND, FRANCE \\ (d) Clermont Université, Université Blaise Pascal, MSH, BP 10448, F-63000 CLERMONT-FERRAND, FRANCE
}

\begin{abstract}
The use of Light Detection And Ranging (LiDAR) for archaeological purposes is becoming more prevalent in order to detect and to document remains located in forested areas. A manual digitalisation of the detected elements is possible if the aim is to focus on some particular elements. However, one of the main interests of airborne laser scanning is to put the archaeological information in their context, and to allow a better understanding of the relation between each item and its environment (other structures, paths, etc). This concept of archaeological landscape generally results in a too large amount of data to permit a manual analysis. This paper describes an approach for the automatic detection of particular archaeological artefact, archaeological grazing structures, found in high concentration in some places of Auvergne (France). First, a model of the elements of interest is designed with the archaeologist. The automatic detection of the archaeological grazing structures is then carried out, based on the evaluation of the matching degree of each element with the model. Finally, the location and the boundary of each selected elements are extracted and stored in a database. The efficiency of the method is tested, by comparison with the manual digitalisation of an expert, on a restricted zone, and the observed differences are analysed and discussed.
\end{abstract}

Key words: Archaeological structure detection, geoarchaeology, LiDAR, ALS, segmentation, template matching, Digital Terrain Model, Local Relief model, automatic detection, signal processing, pattern recognition.

\section{Introduction:}

LiDAR, generally known as airborne laser scanning (ALS), is used by archaeologists to detect and map sites and to analyze past landscape since the last ten years (Cutchley and Crow, 2009; Masini et al., 2011; Georges-Leroy et al., 2014). Because of its ability to penetrate certain types of woodland canopy, this technology is a revolutionary tool for archaeologist interested in remains mostly located under forest areas which are still relatively unexplored. Research programs using Lidar data are becoming more and more frequent. From an historiographical perspective, they are in the continuity of the landscape archaeology studies, developed in the 1980s, especially in the Mediterranean Basin. They aspire to explore vast areas, linking scales from micro-regional to regional studies. Lidar survey exhibits archaeological remains, preserved from destruction by their position in altitude or a protective vegetative cover. Over the past ten years, LiDAR technology permitted to discover unknown or partially identified archaeological sites worldwide even under dense vegetation cover (Devereux et al., 2005; Humme et al., 2006; Doneus et al., 2008; Johnson and Ouimet, 2014; Chase et al., 2014; Ludemann, 2012; Evans et al., 2013; Johnson et al, 2014; Stark et al., 2015). The majority of published studies examined the possibility of using ALS data for 
archaeological investigations by visualization and interpretation of high resolution ALS derived-DTMs (Digital Terrain Model) (Kokalj et al, 2011; Bennet et al., 2012; Opitz and Cowley, 2013) after classification procedures of bare-earth elevations (Kilian et al., 1996; Kraus and Pfeifer, 1998; Vosselman, 2000; Zhang et al., 2003; Zaksek and Pfeifer, 2006; Lasaporana et al., 2011). The ALS ground point clouds are converted to raster DTMs which are used to build derived visualization models. A broad range of models derived from the raster DTMs exist and are used as supplementary tools to detect and differentiate microtopography and therefore archaeological features, for examples, multidirectional oblique weighting hillshade (MDOW), slope, local relief model (LRM), sky-view factor (SVF), positive and negative openness or combination of those methods (Devereux et al., 2008; Hesse, 2010; Challis et al., 2011; Kokaljiz et al., 2011; McCoy et al., 2011; Bennett et al., 2012; Stular et al., 2012; Doneus, 2013). These DTM treatments are usually grouped in the so-called visualization methods and the archaeologist's analytical work is to filter, rank and interpret topographic anomalies and local details enhanced by these derived-models in order to discriminate only those with an historical interest. The selected structures are then manually digitized, mapped and integrated into GIS-based environment (Doneus and Küthreiber, 2013). However, the density of archaeological features and the large areas covered by the LiDAR surveys render the manual analysis and interpretation a timeconsuming and fastidious task (Sevara et al., 2016). The manual visual interpretation is also a subjective process and can have a substantial impact on remains investigations, depending of the level of expertise of people carrying this classification : Non-sites may be identified as potential archaeological sites or on the other hand elements of archaeological relevance may be interpreted as natural (Doneus and Briese, 2006). Specialists may also focus on singular points of their own interest, and may tend to see what they know and unconsciously neglect other elements (Cowley, 2012).

Recently, automatic analysis of satellite images (Lasaponara et al, 2014; D'Orazio et al, 2012; Figorito et al, 2014; Di Iorio et al, 2010) or LiDAR data (Cowley, 2012; Trier and Pilø, 2012; Casana, 2014; Trier et al., 2015; Sevara et al., 2016) were applied to extract remains and to offer to archaeologists an additional visualization method to detect archaeological features in large areas or in area where remains are not visible to the naked eyes. Moreover, automatic detection may be applied to ALS data, either directly on the LiDAR point cloud or on a derived DEM with an appropriately chosen raster resolution, i.e. pixel size. Several approaches have been proposed recently : Pixel-based classification, based on the identification of high altitudinal gradients in ALS-derived raster DTM like LRM and SVF models, has been applied and compared with object oriented classification (Sevara et al., 2016). The template matching approach has also been tested for archaeological structures with simple forms (Trier et al., 2015, Schneider et al., 2014). The method is then based on a geometrical template, defined from the knowledge of the morphometric characteristics of a targeted archaeological feature. The main problem is that the automatic detection is mostly limited to simple and isolated structures (Kim et al., 2005; Krøgli et al., 2007; Rack et al., 2005; Wan et al.,2012). The aim of this paper is to propose a combination between pixelbased classification and template matching, in order to detect the elementary parts of complex archaeological structures. Each elementary structure is defined by its morphometric characteristics, but also by its belonging to a complex structure, that may have various shapes and sizes.

The Lidar survey of the central part of the Chaîne des Puys (volcanic chain located in Auvergne, France), held in winter 2011, revealed, for the first time in the Dome Mountains, the presence of a typical grazing structures locally called "tras" (figure 1). These structures are rectangular or sub circular and compartmentalized. They correspond to grazing features of late medieval to early modern era (D’Aussy 1788; Fournier 1983). These structures are 
already well known in the pastoral lands of the Cézallier and Monts Dores regions, in the French Massif Central (Sauget et al. 2001). They can be found in highly concentrated forms (hundreds of structures), raising a registration problem. As a consequence, only global areas are so far registered, without any information on individualized structures. The discovery of an important concentration of grazing structures (225 elementary structures for half a square $\mathrm{km}$ ) in an area covered by the LiDAR was the opportunity to develop and to test an automatic detection tool. As several thousand of them are present in different sectors of the Massif Central, the method will be easily deployable on a much larger scale and will assist archaeologists and the archaeological services to map these grazing structures.
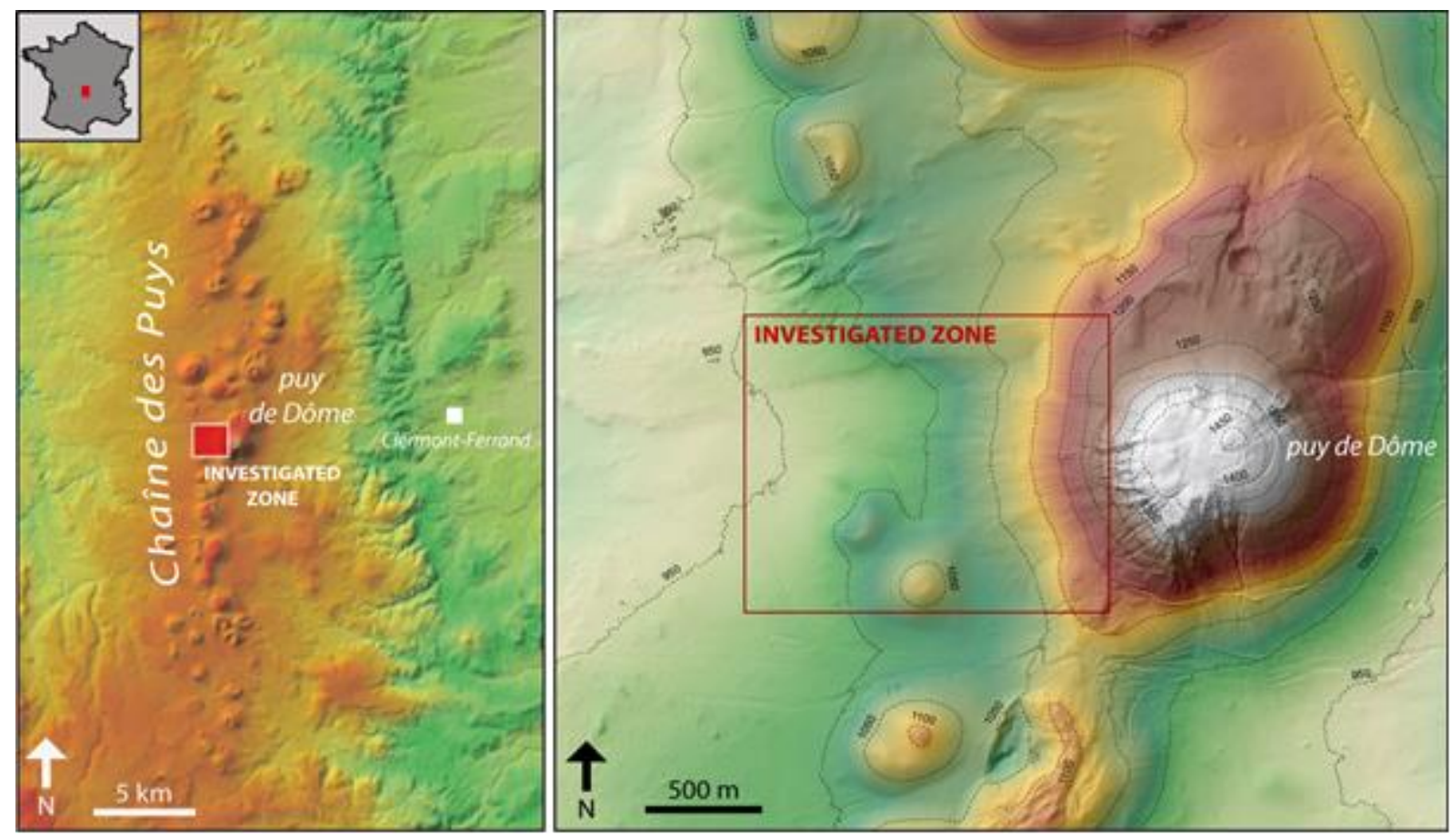

Fig. 1. Study site location in the French Chaîne des Puys and localisation of the investigated zone where the LiDAR data where used for the automatic detection validation

The first part of this study concerns the characterization and the modeling of the archaeological grazing structures: The generation of a derived model of the DTM allows the identification of the structures. Then, the selection of a typical element by an expert enables to build a model. The second parts deals with the automatic detection process and the associated test of efficiency, by comparison with an expert approach. The results of the automatic detection are compared with manual interpretation and field walking which serve as reference databases, in order to evaluate the balance of the false/true detection of the automatic algorithm and if the data processing developed is a valuable tool to detect and map specific archaeological features.

\section{Data and methods}

\subsection{Airborne Laser Scanner data and derived data set}

LiDAR data were acquired by airborne on 23-march 2011 with a minimum of 18 emitted laser pulse per square meter. The field is dominated by deciduous (hazel, beech, birch) and rare isolated conifers allowing a dense proportion of hits of the ground: 11.5 grounds hits per square meter on average and a standard deviation of \pm 8.9 points $/ \mathrm{m}^{2}$, with a 
minimum of 0 and a maximum of 47. The maxima point's densities correspond to overlapping areas and sectors without any trees, whereas low point densities correspond to regions covered by conifers. Finally $42 \%$ of the studied area contains more than 10 points per $\mathrm{m}^{2}, 50$ $\%$ between 10 and 5 points per $\mathrm{m}^{2}, 7 \%$ less than 5 points per $\mathrm{m}^{2}$ and $0.65 \%$ contain no point. The LiDAR data were available as binary data files in the LAS file format, containing up to four returns per emitted laser pulse. Each return contains $\mathrm{x}, \mathrm{y}$ and $\mathrm{z}$ coordinates in Lambert 93 (EPSG 2154), and a class label denoting ground and vegetation or building point. We selected only ground returns which were first interpolated using the ANUDEM method (Hutchinson,

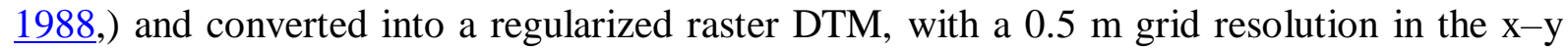
plane. This gives 4 grid cells per square meter so as to preserve all the detail of bare earth point clouds.

In order to make possible the automatic detection of archaeological elements, a preliminary treatment of the DTM is essential to reveal the items of interest (Stular et al, 2012). Several methods are usable for this, such as Local Relief Model (LRM) (Hesse, 2010), hillshade with one or several direction of illumination (Doneus, 2013), or models based on the Sky View Factors (SVF) (Zalsek et al., 2011). For all these methods, the aim is to highlight the micro-relief, usually due to human activity.

In this study, MDOW, LRM, SKV and openness were calculated using the RVT software (Relief Visualization Toolbox, 2015; Zakšek et al., 2014; Zakšek et al., 2011; Kokalj et al., 2011). We chose LRM as the best candidate to test the success of the automatic detection algorithm because it's well suited in the case of slight relief and because it causes a negligible horizontal shift in the position of features (Bennett et al., 2012; Mcneary, 2014), which is important for the automatic localisation of the archaeological structures. The principle of the LRM computation is to apply a high pass filter to the DTM, so that only the highest frequencies component of dataset, corresponding to high altitude gradient $\frac{d z}{d x}$ or $\frac{d z}{d y}$, which may be associated to anthropogenic landforms, are conserved. The lower frequencies due to natural relief are suppressed (Bofinger and Hesse, 2011). A moving average filtering is applied to the DTM. This low pass filter replaces each matrix element by the average value of the surrounding elements:

$$
x_{n, m}=\frac{1}{N \cdot M} \cdot \sum_{k 1=n-\frac{N}{2}}^{n+\frac{N}{2}} \sum_{k 2=m-\frac{M}{2}}^{m+\frac{M}{2}} x_{k 1, k 2}
$$

where $\mathrm{M}$ represents the number of lines and $\mathrm{N}$ the number of columns of the filter

The aim of this filter is to remove all the highest frequency components of the topographic variation, especially the ones of anthropogenic source. The choice of the filter size $[\mathrm{MxN}]$ is an important parameter, because it corresponds to the cut-off frequency of the filter: It has to correspond to the size of the element that we want to detect, in this case $6 \times 6 \mathrm{~m}$, the dimension of a typical elementary grazing structure. If the filtering area is too small, the anthropogenic structures will be only partly eliminated. On the contrary, if the filtering area is too large, the natural relief that we want to select will be distorted. Finally, this filtered DTM is subtracted to the initial one. The lower frequency variations are then erased and the remaining information correspond to high frequency components. 


\subsection{Description and modelling of the grazing structures}

The figure 2 presents a typical configuration of the archaeological grazing structures structures. Each elementary structure is characterised by a sub circular depression, generally associated with an access corridor and surrounded by some ridges. The average measures are about $6 \times 6 \mathrm{~m}$ for each elementary structure and 9x1.5 $\mathrm{m}$ for the corridor This typical configuration can however present several variations: for example the corridor may be missing or a smaller depression can be found, in the middle of the corridor. (Florez et al., 2014). Due to their originality, their morphology, their global complexity and their spatial concentration, these structures are particularly well suited for the development of the automatic detection algorithm. They can be found isolated, as it can be the case for charcoal kiln (Schneider et al, 2014), but several structures are mostly associated together, with a great variety of typologies (Florez et al., 2013). Thus, a classical template matching approach may not be sufficient to detect them. The elementary structures arrangement can be another identification indicia, but as these groupings can have various sizes and shapes, they can't be identified by classical morphometric criteria. The proposed method combines information on both elementary and complex archaeological structures, in order to allow the detection of each elementary structure. The automatic detection and identification of complex archaeological structures become possible, from an a priori knowledge of elementary components of these structures. In this paper we use both general geometrical signatures of the complex structures and coupled template matching and pixel-based classification approach of its main elementary component to automatically detect them. In the rest of this article, each elementary part will be referred to as "elementary grazing structure", an association of several coalescing elementary structures being referred to as "complex grazing structure. (figure 2)

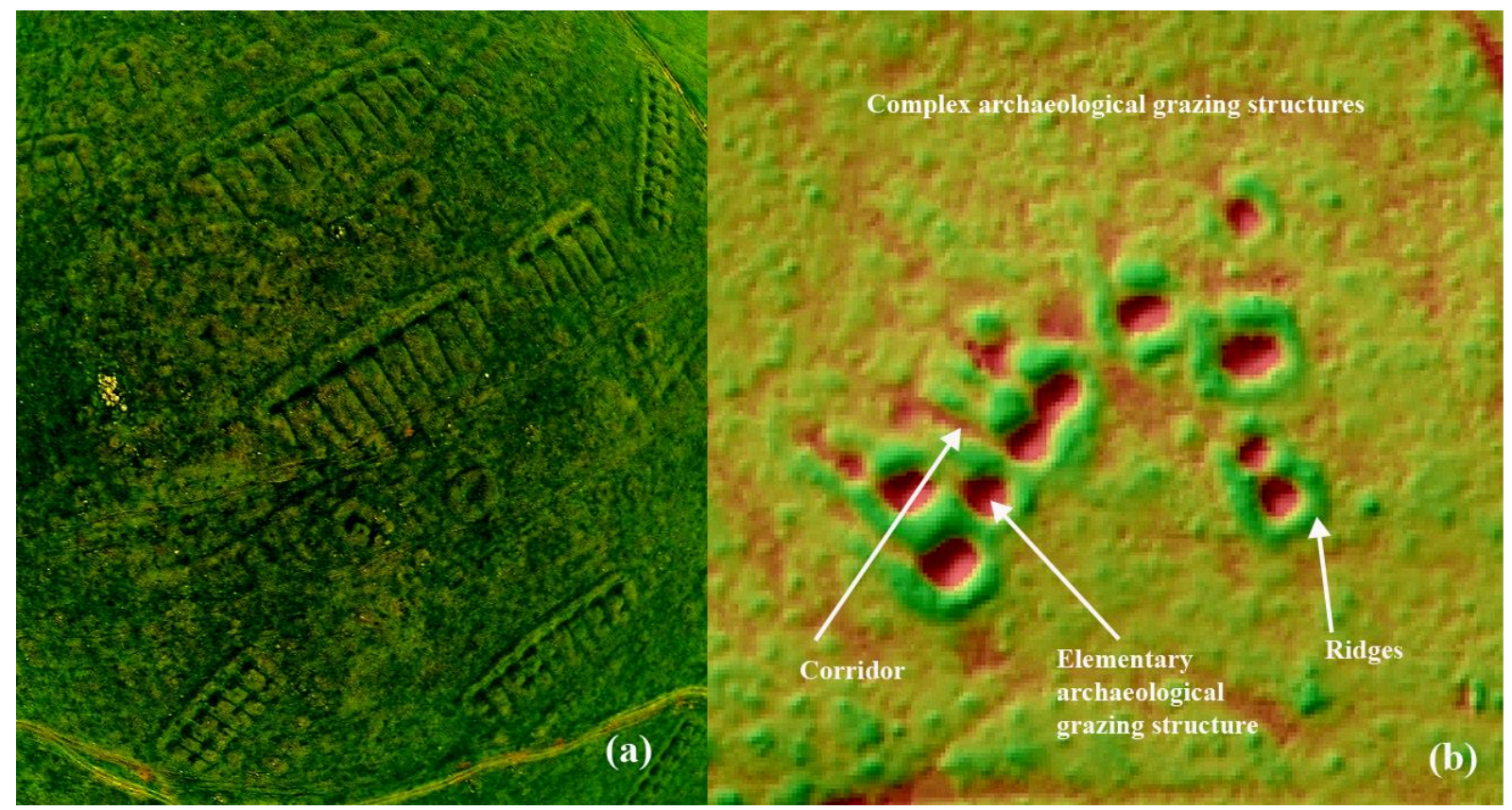

Fig. 2. Typology of the grazing structures showing their main characteristics. aerial photography of archaeological grazing structures (Cezallier) (a), Local relief Model of a small part of the investigated zone (b). The red parts represent what we call "elementary archaeological grazing structures", surrounded by some "ridges" and sometimes associated with an "access corridor". All of these elements belong to the "complex archaeological grazing structures". 
In order to implement the automatic detection process, the elementary grazing structures have to be modelled. This model is synthesized, from a sub-raster chosen by the archaeologist and extracted from the LRM. The expert selects a structure considered as the more representative of the searched elements. It is a form well-preserved or barely degraded by the erosion and with a well-marked specific shape. The characteristic information of the reference structure (length, width, depth) are automatically extracted to be used for the automatic detection. A model of the elementary archaeological grazing structure is then designed, based on a clipped sinus cardinal function normalised to correspond to the reference structure dimensions and described by the following mathematical expression :

$$
z=-\sin c\left(\sqrt{x^{2}+y^{2}}\right)=\frac{-\sin \left(\sqrt{x^{2}+y^{2}}\right)}{\sqrt{x^{2}+y^{2}}}
$$

The obtained negative values are truncated, in order to equilibrate maximum and minimum values according to the characteristics of the reference structure:

$$
\text { if } \mathrm{z}<\mathrm{Z}_{\max } \text { then } \mathrm{z}=-\mathrm{Z}_{\max }
$$

The modelling process of the elementary grazing structure is summarized on figure 3 .

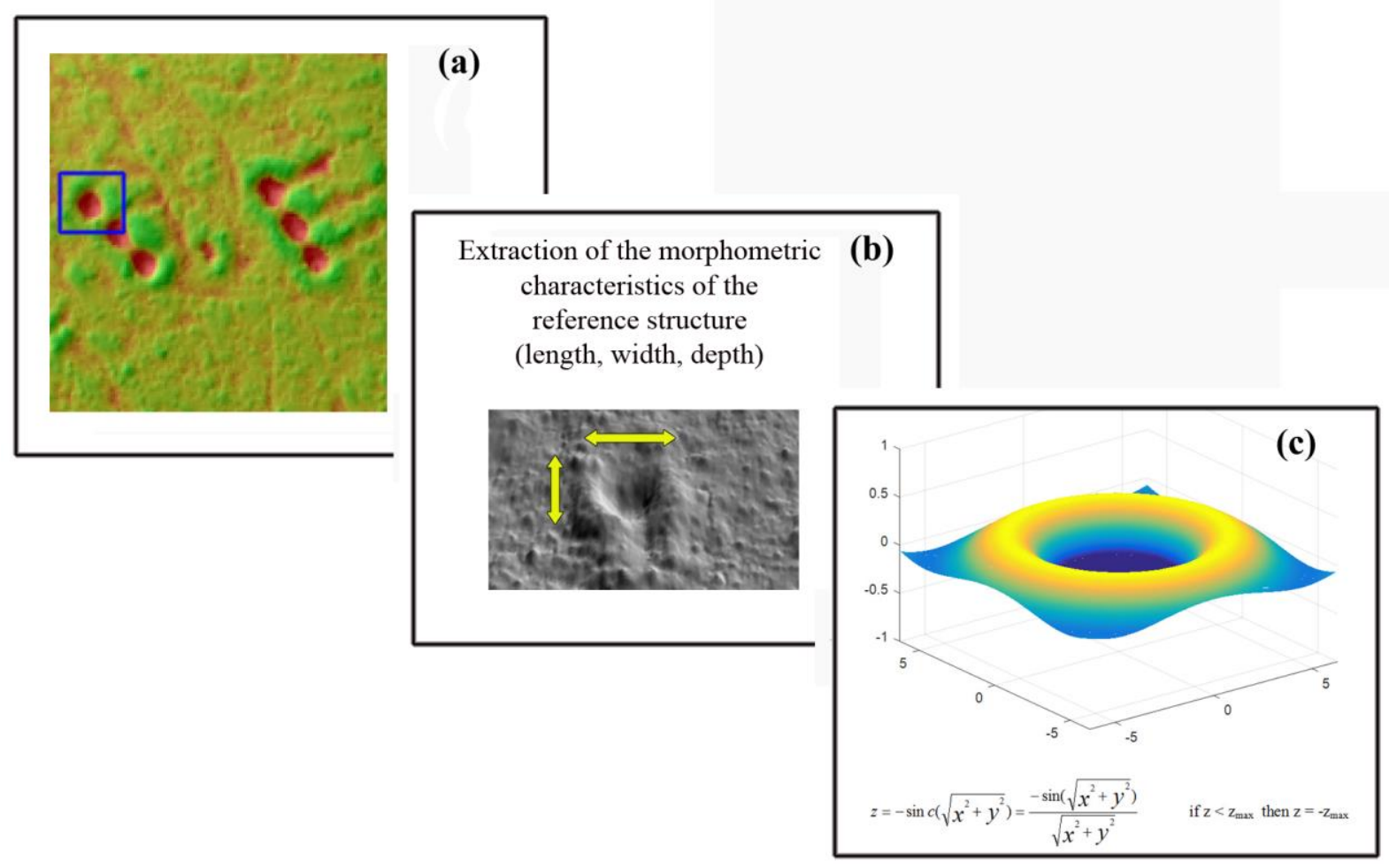

Fig. 3. Process of creation of a model of the archaeological grazing structure : choice of a representative element (a), extraction of its characteristics (b), creation of a numerical model (c)

\subsection{Automatic detection process}

The anomalies highlighted by the LRM can now be detected automatically. The first step consists in the binarization and segmentation process, based on two complementary segmentation stages: all the matrix element corresponding to positive LRM values (relative elevation above the local mean) of at least $33 \%$ of the maximum elevation value of the LRM 
are selected. The coalescing elements obtained are then merged together and interpreted as potential interesting element. The same process is applied for the segmentation of elements with negative LRM values (relative elevation under the local mean). The second step consists in detecting all the objects that could be associated to a human activity, i.e. characterised by a high gradient. The third step is to classify them basically in four classes, based on their planar shapes:

$\Rightarrow$ Narrow linear elements with a negative relative altimetry (topographic depression) and interpreted as trails, pathways or deep gullies

$\Rightarrow$ Narrow linear elements with a positive relative altimetry and interpreted as small plot walls and ridges

$\Rightarrow$ Smalls and compact elements, with a size lower than half the one of the reference structure, interpreted as artefacts and eliminated by an erosion/dilatation process

$\Rightarrow$ The remaining objects, interpreted as potential grazing archaeological structures.

Two detection processes are then carried out in parallel :

A pixel based detection is implemented, based on morphometric characteristic of the structures. The potential complex structures, i.e. groups of nested elementary items are detected. These groupings are complex to identify, because they can contain a various number of basic elements, and so have variable dimensions and geometric configurations. A set of three general features have to be evaluated to characterise a complex structure:

a) each candidate must have some hollow parts surrounded by element in relative elevation, leading to high elevation gradient in the LRM.

b) the minimum size of each element must be at least equal to the one of the reference structure

Then, all the hollow parts being inside the complex structures and having dimensions consistent with the ones of the model are selected and interpreted as potential elementary structures.

In parallel, another step is necessary to focus on the researched archaeological structure, by carrying a template matching approach (De Boer, 2005; Schneider et al, 2014). A moving cross-correlation is realised between the model previously defined and the whole studied area. For each point with coordinates [i,j] of the LRM, the cross-correlation coefficient is defined as :

$$
\left.\operatorname{Corr}[i, j]=\sum_{j_{1}=-\frac{N_{j}}{2} \sum_{i_{1}}=-\frac{N_{i}}{2}}^{N_{j} / 2} \sum_{N_{i} / 2} \operatorname{ref}\left[i+N_{i} / 2, j+N_{j} / 2\right]-\overline{r e f}\right) \cdot\left(L R M\left[i+i_{1}, j+j_{1}\right]-\overline{L R M}\right)
$$

where:

Corr is the result of the cross-correlation

Ref correspond to the reference object (model)

LRM is the whole Local Relief Model

$\overline{r e f}$ is the mean value of the relative elevations for the reference object

$\overline{L R M}$ is the mean value of the LRM relative elevations in the analysis window, the size of the reference object

$\mathrm{N}_{\mathrm{i}}$ is the width of the model

$\mathrm{N}_{\mathrm{j}}$ is the height of the model

The figure 4 shows the result of the cross-correlation process on a small area. It turns out that even if correlation peaks match well the grazing structures elementary cells, some high values 
of the correlation coefficient also correspond to other elements, like lanes or access corridors fragments.
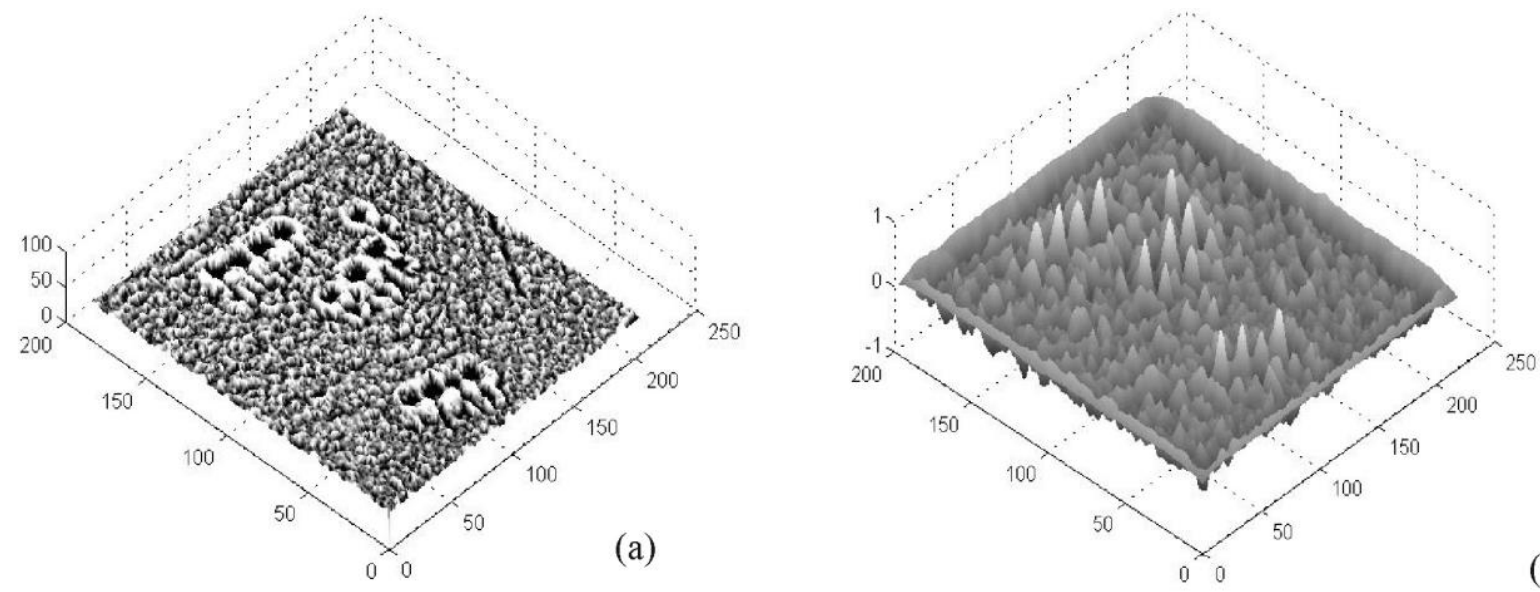

(b)

Fig. 4. Visualization of the archaeological grazing structures (a) and of the associated correlation peaks (b)

These results, obtained on a small area allow defining a minimum correlation rate for the detection. In our case, this limit value chosen for the acceptable correlation rate is $60 \%$. Our choice was to favour the completeness of the diagnostic, rather than its accuracy. The reason of this choice will be explained in the discussion.

At last, the two approaches are merged, in order to limit the number of artefacts: only the elements detected by the two complementary approaches are retained. Elements characterised by a high correlation rate with the model but not included in a complex structure can then be suppressed. The characteristics of the selected elements (centroid coordinates, length, width, depth, correlation rate with the model) are then automatically extracted and stored in a database.

The figure 5 summarizes the algorithmic approach implemented for the automatic detection process in MATLAB® environment. The computation is carried out on a laptop computer with Intel® Core $17-3720 \mathrm{QM}$ processor. The total computation time, for the detection of all the elements and the storage of the associated information in the database is $214.79 \mathrm{~s}$

\subsection{Testing the efficiency of the automatic detection process}

The quality of the automatic detection was tested, using a comparison between the grazing structures detected automatically and the result of an expert detection. In a first step, a map of the true elementary grazing structures, which serve as reference, is produced. The mapping work is based on the digitization of each element using common visualisation tools (DEM, multi-direction hillshading and local relief models) within a GIS environment. Fieldworks were also performed to confirm the location of grazing structures using a handheld GPS (Geoexplorer XT) enabling decimetric precision.

In a second step, the pixel by pixel comparison (resolution of $50 \mathrm{~cm}$ ) between the expert mapping and the results of the automatic detection allows the construction of a confusion matrix which count the number of pixel of the four possible outcomes: true positive (successful detections of structures), false negative (undetected structures), true negative 
(correct detection of the absence of structure) and false positive (erroneous detections of structures).

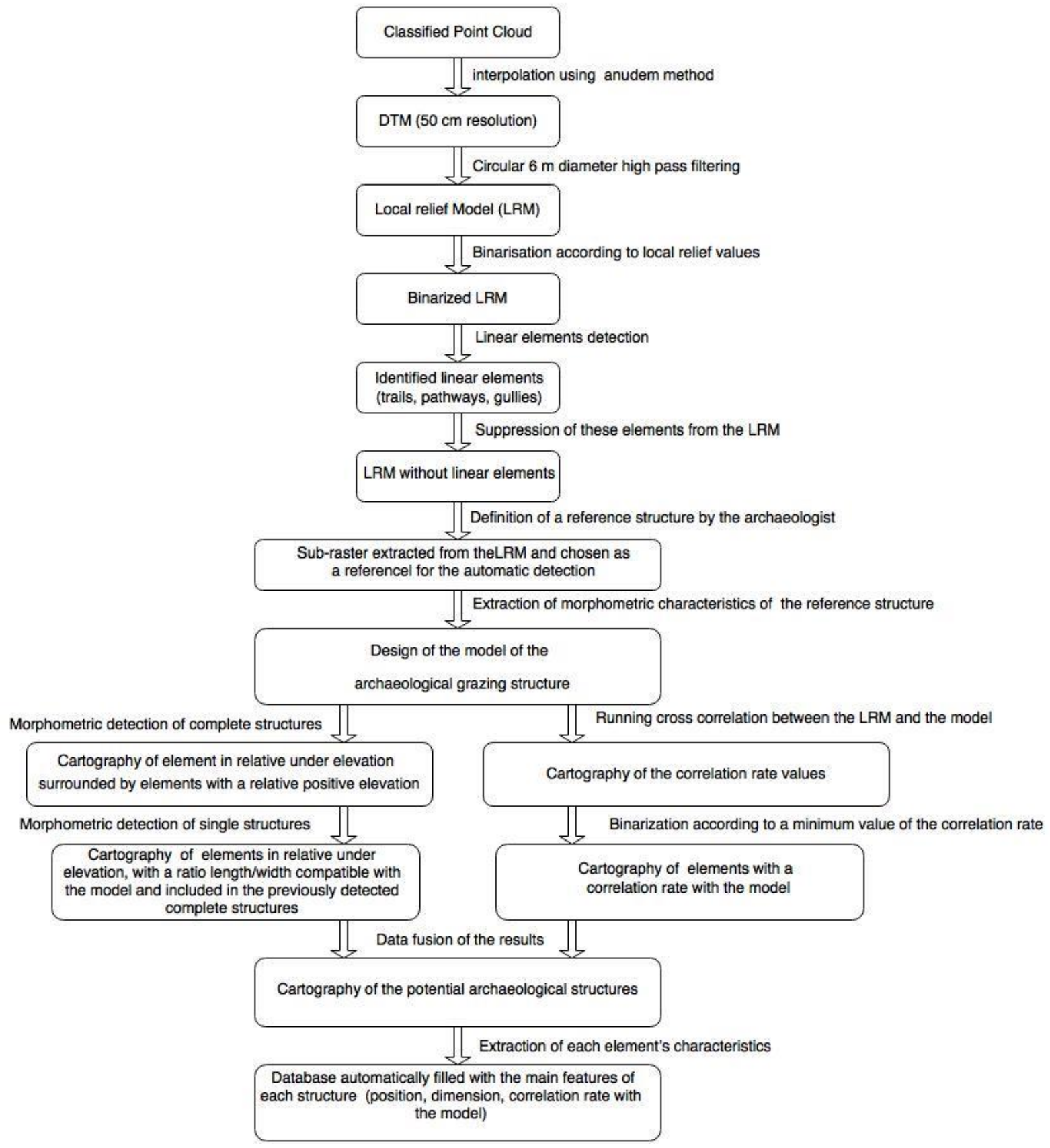

Fig. 5. Flowchart of the approach implemented for the automatic detection process

The confusion matrix enables the calculation of common performance metrics of the automatic detection process (Fawcett, 2006; Kim, 2005). Four parameters are then computed:

- the sensitivity is the probability that the detection result is positive when the structure is present:

$$
\text { sensitivity }=\frac{\text { true positive }}{\text { true positive }+ \text { false negative }}
$$

- the specificity is the probability that the detection result is negative when the structure is not present: 


$$
\text { specificity }=\frac{\text { true negative }}{\text { false positive }+ \text { true negative }}
$$

- the positive predictive value (PPV) is the probability that the structure is present when the detection result is positive

$$
\text { positive predictive value }=\frac{\text { true positive }}{\text { true positive }+ \text { false positive }}
$$

- the negative predictive value (NPV) is the probability that the structure is not present when the detection result is negative:

$$
\text { negative predictive value }=\frac{\text { true negative }}{\text { false negative }+ \text { true negative }}
$$

\section{Results and Discussion}

\subsection{Efficiency of the automatic detection process.}

The quality of the automatic detection process is now evaluated at the scale of the structure and at the scale of each pixel. The table 1 gives the results of the comparison between the expert approach and the automatic detection, in terms of number of elementary structures.

Table.1

Results of the elementary structures detection

\begin{tabular}{ccccc}
\hline $\begin{array}{c}\text { Expert } \\
\text { detection }\end{array}$ & $\begin{array}{c}\text { Automatic } \\
\text { detection }\end{array}$ & $\begin{array}{c}\text { Successful } \\
\text { detection }\end{array}$ & $\begin{array}{c}\text { Undetected } \\
\text { structures }\end{array}$ & $\begin{array}{c}\text { Erroneous } \\
\text { detection }\end{array}$ \\
\hline $\mathbf{2 2 5}$ & $\mathbf{2 8 0}$ & $\mathbf{2 0 4}$ & $\mathbf{2 1}$ & $\mathbf{7 6}$ \\
\hline
\end{tabular}

From the structures point of view, the automatic detection process locates 282 grazing structures whereas the results of the expert mapping and fieldwork count 225 features in the study area. This difference is due to erroneous detections (76 elements are misread as archaeological grazing structure) and to undetected structures (21 elements). 204 detection are classified as successful (automatic detection validated by the expert), representing $90.7 \%$ of the actual archaeological grazing structures. The table 2 gives the values of the quality indicators computed, in terms of number of pixel.

Table.2

Quality indicators at the pixel scale

\begin{tabular}{cccc}
\hline True positive & True negative & False positive & False negative \\
\hline $\mathbf{1 0 3 2 8}$ & $\mathbf{8 4 1 4 7 5 7}$ & $\mathbf{2 7 1 2}$ & $\mathbf{9 1 0}$ \\
\hline Sensitivity & Specificity & PPV & NPV \\
\hline $\mathbf{0 . 9 1 9}$ & $\mathbf{0 . 9 9 9}$ & $\mathbf{0 . 7 9 2}$ & $\mathbf{0 . 9 9 9}$ \\
\hline
\end{tabular}

The values of the sensitivity and specificity metrics (respectively 0.919 and 0.999) indicate that the algorithm is efficient for the detection and the location of grazing structures. More precisely, the positive predictive value (PPV) and the negative predictive value (NPV) ( 0.792 and 0.999 respectively) express the ability of the algorithm to locate grazing structures with a higher amount of erroneous detection (false positive) than undetected features (false negative). A total of 2712 pixels are classified as false positive and correspond to 76 topographic marks which are not grazing structures. By contrast, the number of undetected 
grazing structures remains relatively low, 910 false negative pixels corresponding to 21 undetected features

Almost the totality (94.7\%) of erroneous detections is related to archaeological or anthropic features (figure 6-A). They are mostly surrounding fragments of detected "tras" which are interpreted as independent grazing structures, like corridors $(n=34)$ and eroded ridges $(n=7)$. The remaining erroneous detections are modern topographic features like trails parts $(n=15)$ and recent structures $(n=16)$ as circular excavations for military training. Only 4 erroneous detections are attributed to natural depressions. The undetected grazing structures mostly correspond to strongly eroded features with smoothed ridges and partially filled hollows (figure 6-B). Furthermore, coalescent "tras" are detected as single structure five times, leading to the underestimation of the grazing structure count.

Moreover, mapping of the results do not show distinct spatial patterns for successful, erroneous and undetected structures. It suggests that the global variation of the terrain morphology does not influence the algorithm efficiency (Roussel et al, 2014).
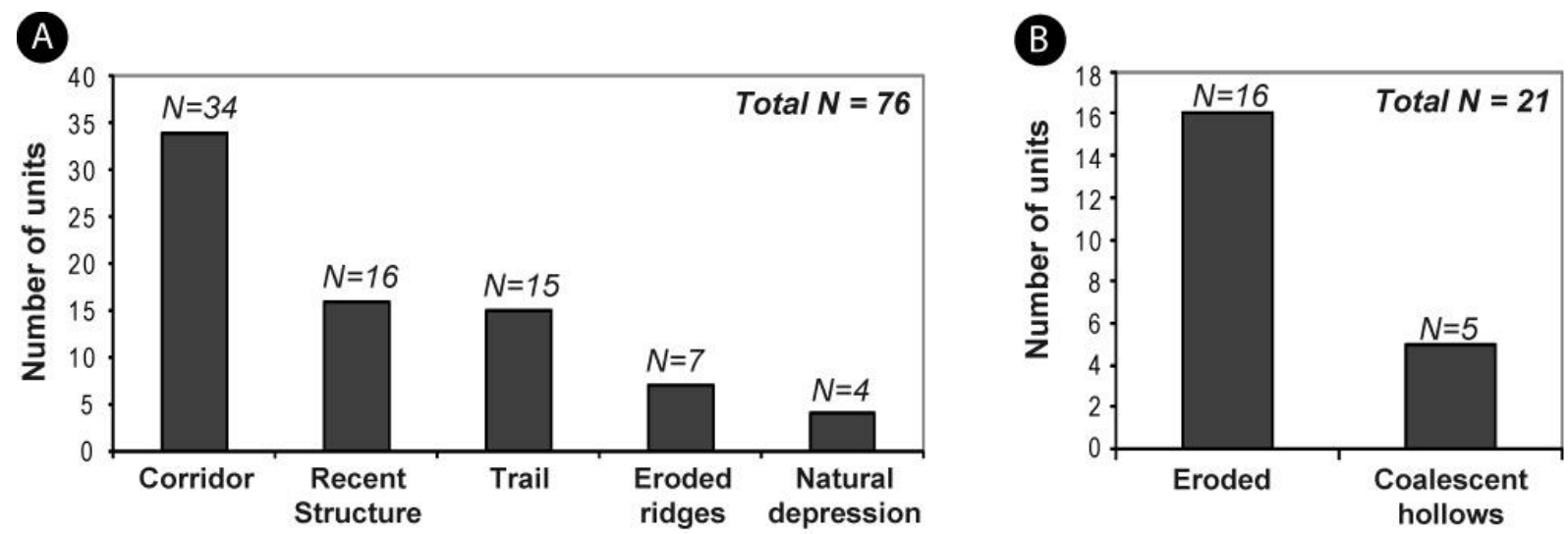

Fig. 6. Types of erroneous detections (A) and types of undetected structure (B)
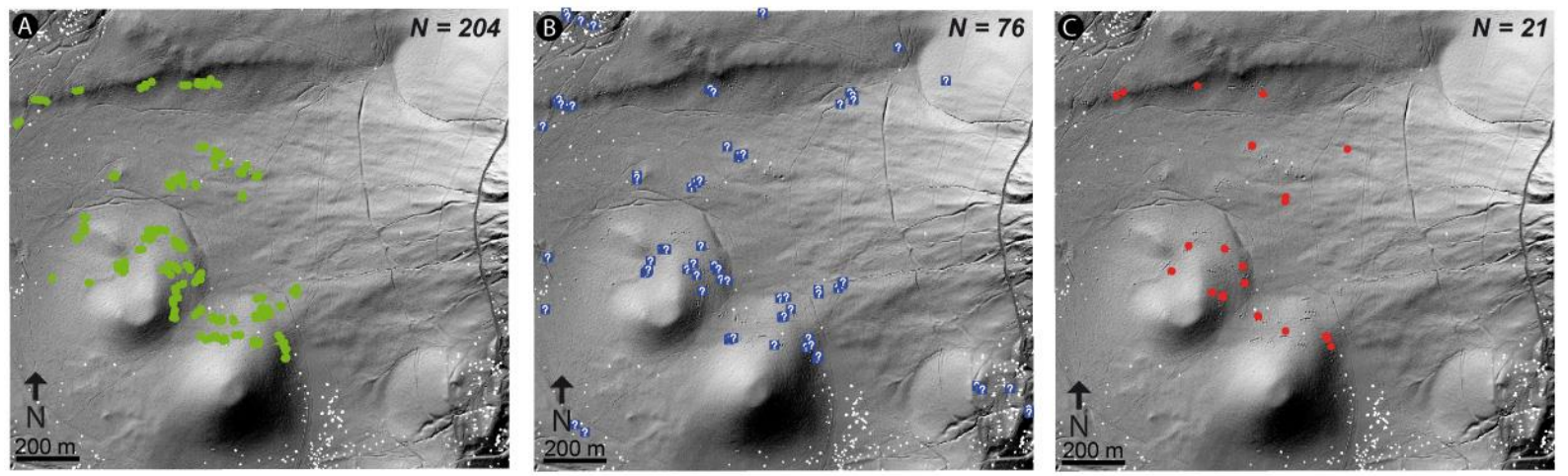

Fig. 7. Mapping of the results for successful (A), erroneous (B) and undetected (C) structures.

\subsection{Discussion}

The principle of automatic detection already exists since several years in industrial context (Rabbani et al, 2005; Pourreza et al, 2008; Tang et al, 2000, Fazlollahi et al, 2013). The application to LiDAR data is much more complex, for two main reasons. First, the quality and the resolution of the digital terrain model is generally insufficient to allow a precise description of the searched pattern. In our case, the elementary structure is defined by only about a hundred pixels, whereas a classical low definition image used in industrial vision context contain at least one million of pixels. The consequence is that some elements appear sometimes distorted or fragmented, making their identification difficult. For example, paths 
are theoretically easy to identify, because of their linear characteristic. However, if they appear truncated, as a dotted line, each elementary part will be interpreted as standalone object. In the case of the archaeological grazing structures, the hollow part (the black pixels of the LRM) can exhibit very different shapes, even for structures with the similar size and functionalities. The figure 7 , showing the result of the automatic detection, illustrates this problem.
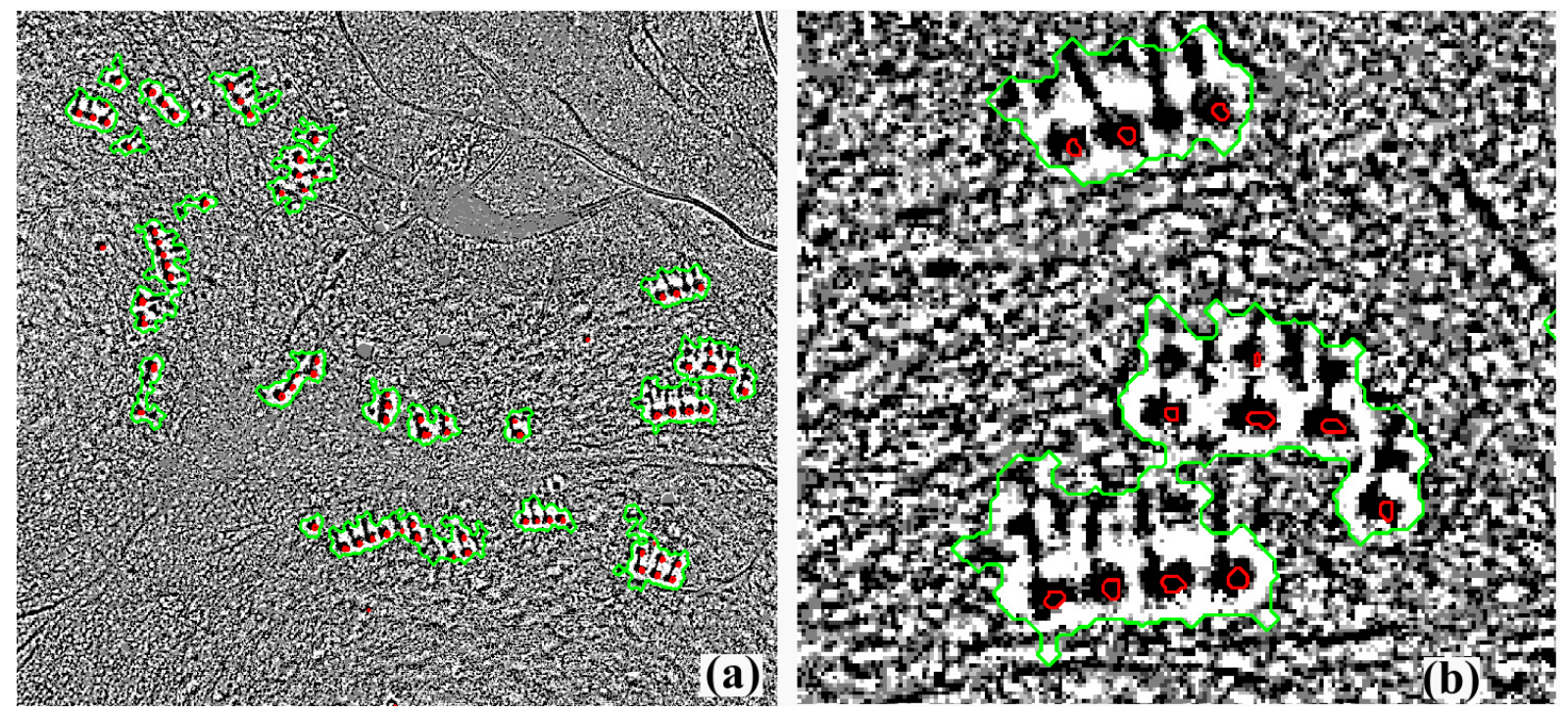

Fig. 8. visualisation of the results of the automatic detection : complex structures in green and elementary structures in red (a), example of undetected elements and illustration of the variability of the shape for the elementary grazing structures $(b)$

The detection process, based on finding elements characterised by enough similarity with a model, has to take into account this inaccuracy. If the degree of similarity imposed is too high, the more eroded or atypical elements won't be detected. On the contrary, if the degree of similarity imposed is too low, the number of erroneous detection will increase dramatically. It is so necessary to establish a clear detection strategy, to optimize the dilemma between the accuracy and the completeness of the algorithm. The aim is indeed to limit the number of artefacts, but especially not to forget any element, even if it's a little bit different from the model. The choice presented in this paper is to give priority to completeness, because it is easier to remove inappropriate elements from a database than complete this database with all the characteristic of the forgotten items. (Toumazet et al., 2014). But this choice is arbitrary, and it is possible to focus on the accuracy, especially if the searched elements are precisely defined. The proportion of undetected grazing structures revealed by the performance indicators and compared to erroneous detection depends on the degree of similarity expected with the model. The values obtained in this study correspond to the chosen strategy to be as exhaustive as possible on the actual structure detection, even if it causes an increase of improper detections.

Two parameters allow adapting the compromise between accuracy and completeness: the tolerances on the characteristic dimensions of the structures and the correlation rate with the model. It is important to note that the value of the correlation rate give important information on the degree of resemblance with the model. The result of the automatic detection process is thus not only binary (it is an element of interest or not), but, for each of the retained elements, it indicates the reliability of this detection. It is then possible to create classes, with an associated range of probability to correspond to the researched archaeological landform. 
This consideration implies a question about the choice of the model. It has an important consequence on the result of the detection process. The question is: "What is the best model to detect all the archaeological structures?" The natural trend is obviously to choose an element as "perfect" as possible, but maybe it won't be the most adapted to detect eroded elements. For the detection step based on the correlation with the model, we chose to simplify the model as much as possible: the structure is then represented by a circular depression surrounded by a higher relative elevation area (figure 3). Another approach to explore, in further investigations, is to use several models (closer from the actual archaeological elements), reflecting the different typologies or degrees of conservation of the structures. In this approach, after the first step of selection of potential element of interest, a multi-model correlation would be carried out, in order to detect the archaeological structures, but also to classify them according to their correlation rate with each model. The probability of belonging to each class would then be computed, and the confidence level of this classification for each element would be evaluated, helping the archaeologist for the validation work.

The automatic detection of archaeological remains from LiDAR data set is a new tool to help archaeologists, just like it was for GIS and spatial analysis in the early 2000s. The aim is not merely to create a "press-button" tool but to promote a close cooperation between the archaeologist and the computer engineers. The efficiency of the pattern recognition algorithm is strongly dependent on the archaeological landforms features. This means that this tool can be successful only if the model selected to feed the algorithm is relevant, i.e. with a well characterized morphological signature that only the archaeologists are trained to find and interpret. In addition, this tool is only relevant when it is applied to large areas survey with a high number of similar structures. For examples, charcoal places, shell holes, or "tras" are good candidates for automatic detection. Validation of the results by an archaeologist will be always required, but the identification and classification work can be greatly facilitated by the upstream automatic analysis.

\section{Conclusion}

The use of LiDAR derivative dataset is now widespread in archaeological context. This paper is focused on the development of a methodology involving the automatic detection of grazing archaeological structures. Anthropogenic elements can generally be detected because of their high altitudinal gradient signature, compared to most of natural items. After filtering, the natural relief with the Local Relief Model technique, the elements identified as potential grazing archaeological structures are isolated and classified according to recognition algorithms. The quality and the limits of the automatic detection have been discussed, comparing the results with an expert approach. The results indicate that the proposed method is efficient for the detection and the location of grazing structures. They are obtained with a simple model for the sought structure. The idea is now to work on a more elaborate model, including several conservation status examples. This solution would allow a more exhaustive detection, and above all to give information on the typology of each element.

This tool offers the potential to automatically produce a database of all sites. Future studies will now deal with a more detailed description of the structures, with an automatic extraction of their geographical and morphological characteristics. The aim is to undertake a quantitative analysis of forms that encompasses size, shape and orientation, and perform a spatial analysis of their distribution. With the increasing number of LiDAR surveys, there are real benefits to develop improved algorithms for remains detection, but the fieldwork knowledge and experience will remain essential to advise and to guide the development of computer tools. 


\section{Acknowledgements}

The work presented in this paper is a part of an interdisciplinary research program, called "Lidarcheo". The authors gratefully acknowledge the support of Clermont Communauté for the funding of this project and the support of the Centre Regional Auvergnat de l'Information Géographique (CRAIG) for the funding of LiDAR data. Authors thank Marta Florez for her support as archaeological expert and Marlene Faure, Mohamed Abadi and Stéphane Petit from Veodis-3D company, for their contribution to LiDAR data processing.

\section{References}

Bennett, R., Welham, K., Hill, R.A., Ford, A., 2012. A Comparison of Visualization Techniques for Models Created from Airborne Laser Scanned Data. Archaeological Prospection. 19, 41-48.

Bofinger, J., Hesse, R., 2011. As far as the laser can reach...: laminar analysis of LiDAR detected structures as a powerful instrument for archaeological heritage management in Baden-Württemberg, Germany. In: Cowley, D.C. (Ed.), Remote Sensing for Archaeological Heritage Management. Europae Archaeologia Consilium (EAC), Brussel, pp. 161-171.

Casana, J., 2014. Regional-scale archaeological remote sensing in the age of big data: automated site discovery vs. brute force methods. Adv. Archaeol. Pract. 222-233 (August 2014).

Challis, K., Forlin, P., Kincey, M.A., 2011. A generic toolkit for the visualization of archaeological features on airborne lidar elevation data. Archaeological Prospection, 18(4), 279-289.

Chase, A.F., Chase, D.Z., Awe, J.J., Weishampel, J.F., Iannone, G., Moyes, H., Yaeger, J., Brown, M.K., 2014. The use of LiDAR in understanding the ancient Maya landscape: Caracol and Western Belize. Adv. Archaeol. Pract., 2 (3), 147-160.

Cowley, D.C., 26-27 September 2012. In with the new, out with the old? Auto-extraction for remote sensing archaeology. In: Bostater, C., Mertikas, S., Neyt, X., Nichol, C., Cowley, D., Bruyant, J.P. (Eds.), Remote Sensing of the Ocean, Sea Ice, CoastalWaters, and Large Water Regions 2012. Bellingham, Wash: SPIE (8532), Edinburgh, United Kingdom 853206/1$853206 / 9 \mathrm{~S}$

Crutchley, S., Crow, P., 2009. The Light Fantastic: Using Aiborne Lidar in Archaeological Survey. English Heritage, Swindon. 45p.

D’Aussy, P.J.B.L., 1788. Voyage d'Auvergne. Chez Eugène Onfroy, Paris.

De Boer, A., 2005. Using pattern recognition to search LIDAR data for archeological sites. In The World is in Your Eyes. CAA2005. Computer Applications and Quantitative Methods in Archaeology. Proceedings of the 33rd Conference, Tomar, March 2005, Figueiredo A, Leite Velho G (eds.). Tomar: CAA Portugal; 245-254.

Devereux, B.J., Amable, G.S., Crow, P., Cliff, A.D., 2005. The potential of airborne LiDAR for detection of archaeological features under woodland canopies. Antiquity 79, 648-660.

Devereux, B.J., Amable, G.S., Crow, P., 2008. Visualisation of LiDAR terrain models for archaeological feature detection. Antiquity 82, 470-479.

Di Iorio, A., Straccia, N., Carlucci, R. 2010. Advancement in Automatic Monitoring and Detection of Archaeological Sites Using a Hybrid Process of Remote Sensing, GIS Techniques and a Shape Detection Algorithm, Remote Sensing for Science, Education and Natural and Cultural Heritage. ARSeL (2010 Accessible at http://www.earsel.org/symposia/2010-symposiumParis/Proceedings/EARSeL-Symposium-2010_2-01.pdf).

Doneus, M. 2013. Openness as vizualisation technique for interpretative mapping of airborne LiDAR derived Digital Terrain Models. Remote Sensing 5, 6427-6442.

Doneus, M., Briese, C., 2006. Full-waveform airborne laser scanning as a tool for archaeological reconnaissance. In: Forte, M. (Ed.), From Space to Place, 2. International Conference on Remote Sensing in Archaeology. Archaeopress, Oxford, Rome, pp. 99-106. 
Doneus, M., Kühtreiber, T., 2013. Airborne laser scanning and archaeological interpretation - bringing back the people. In: Opitz, R., Cowley, D. (Eds.), Interpreting Archaeological Topography. Airborne Laser Scanning, 3D Data and Ground Observation.Oxbow Books (Occasional Publication of the Aerial Archaeology Research Group, 5), Oxford, pp. 32-50.

Doneus, M., Briese, C., Fera, M., Janner, M., 2008. Archaeological prospection of forested areas using full-waveform airborne laser scanning. J. Archaeol. Sci. 35 (4), 882-893.

D’Orazio, T., Palumbo F., Guaragnella C., 2012. Archaeological trace extraction by a local directional active contour approach. Pattern Recognition. 45, 3427-3438.

Evans, D.H., Fletcher, R.J., Pottier, C., Chevance, J.B., Soutif, D., Tan, B.S., Im, S., Ea, D., Tin, T., Kim, S., Cromarty, C., De Greef, S., Hanus, K., Baty, P., Kuszinger, R., Shimoda, I., Boornazian, G., 2013. Uncovering Archaeological Landscapes at Angkor Using LiDAR. Poceedings of the National Academy of Science. 110, 12595-12600.

Fawcett, T., 2006, An introduction to ROC analysis, Pattern Recognition Letters 27, 861-874.

Fazlollahi A., Meriaudeau F., Villemagne V., Rowe C., Desmond P., Yates, P.A., Salvado, O., 2013. Automatic detection of small spherical lesions using multi-scale approach in 3D medical images, in: International conference on image processing (ICIP). IEEE, 2013. pp. 1158-1152.

Figorito, B., Tarantino, E., 2014. Semi-automatic detection of linear archaeological traces fromorthorectified aerial images, International Journal of Applied Earth Observation and Geoinformation 26, 458-463.

Flórez, M., .Toumazet, J.P., Roussel, E., Vautier, F., Dousteyssier, B., Abadi, M., Rieutort, L., 2013, Reconstructing the ancient Chaine de Puys cultural landscape (Auvergne, France) through Landscape Archaeology and airborne LIDAR data: the LIDARCHEO Projet, XIXe colloque Archeometrie du GMPCA, Caen, 2013.

Flórez, M., Dousteyssier, B., Vautier, F., Roussel, E., Toumazet, J.P., Faure, M., Abadi, M., 2014.. Archaeomophological approaches and LIDAR data analysis to study a hidden mid-mountain cultural Landscape. The study case of Puy-de-Dôme (France), 3rd International landscape archaeology conference, LAC, Rome, 2014.

Fournier, G., 1983. La vie pastorale dans les montagnes du Centre de la France. Recherches historiques et archéologiques. Bulletin historique et scientifique de l'Auvergne. 91, 199-358.

Georges-Leroy, M., Nuninger, L., Opitz, R.., 2014., Le lidar: une technique de détection au service de l'archéologie. Techniques de l'Ingenieur, IN215.

Hesse, R., 2010. LiDAR-derived Local Relief Models - a new tool for archaeological prospection. Archaeological Prospection. 17, 67-72.

Humme, A., Lindenbergh, R., Sueur, C., 2006. Revealing Celtic fields from LiDAR data using Kriging based filtering. In: Maas, H.G., Schneider, D. (Eds.), Proceedings of the ISPRS Commission V Symposium 'Image Engineering and Vision Metrology', vol. XXXVI, part 5, Dresden, 25-27 September 2006.

Hutchinson, M.F., 1988. Calculation of hydrologically sound digital elevation models. Third International Symposium on Spatial Data Handling ,Sydney (Australie).

Johnson, K.M., Ouimet W.B., 2014. Rediscovering the lost archaeological landscape of southern New England using airborne light detection and ranging (LiDAR). Journal of Archaeological Science. 43, 9-20.

Kim, J.R.; Muller, J.P.; Morley, J., 2005. Automated crater detection, a new tool for Mars cartography and chronology. Photogrammetric Engineering \& Remote Sensing. 71, 1205-1217.

Kokalj, Ž., Zakšek, K., Oštir, K., 2011. Application of sky-view factor for the visualisation of historic landscape features in LiDAR-derived relief models. Antiquity. 85, 263-273.

Kraus, K. Pfeifer, N., 1998. Determination of terrain models in wooded areas with airborne laser scanner data. ISPRS Journal of Photogrammetry and Remote Sensing. 53, 193-203.

Krøgli, S.O., Dypvik, H., Etzelmüller, B., 2007. Automatic detection of circular depressions in digital elevation data in the search for potential Norwegian impact structures. Norwegian Journal of Geology. 87, 157-166.

Lasaponara, R., Coluzzi, R., Masini, N., 2011. Flights into the past: full-waveform airborne laser scanning data for archaeological investigation. J. Archaeol. Sci. 38 (9), 2061-2070. http://dx.doi.org/10.1016/j.jas.2010.10.003. 
Lasaponara, R., Masini, N. 2014. Beyond modern landscape features: New insights in the archaeological area of Tiwanaku in Bolivia from satellite data. International Journal of Applied Earth Observation and Geoinformation. 26, 464-471.

Ludemann, T., 2012. Airborne laser scanning of historical wood charcoal production sites - a new tool of kiln site anthropology at the landscape level. Saguntum Extra. 13, 23-24.

Masini, N., Coluzzi, R,. Lasaponara, R., 2011. On the airborne lidar contribution in archaeology: from site identification to landscape investigation. In: Wang, C.-C. (Ed.), Laser Scanning, Theory and Applications, InTech Online Publishers.

McCoy, M.D., Asner, G.P., Graves, M.W., 2011. Airborne lidar survey of irrigated agricultural landscapes: an application of the slope contrast method. J. Archaeol. Sci. 38, 2141-2154.

Mcneary, R.W.A., 2014. Lidar Investigation of Knockdhu Promontory and Its Environs, County Antrim, Northern Ireland. Archaeological Prospection. 21, 263-76. doi:10.1002/arp. 1488.

Opitz, R., Cowley, D.C., 2013. Interpreting Archaeological Topography: Lasers, 3D Data, Observation, Visualisation, and applications. Oxbow Books, Oxford, England.

Pourreza H. R., Pourreza-Shahri, R., Fazeli, S., 2008. Automatic Detection of Eggshell Defects Based on Machine Vision. Journal of Animal and Veterinary Advances. 7(10), 1200-1203.

Rabbani, T., Van den Heuvel, F., 2005. Efficient Hough transform for automatic detection of cylinders in point clouds. International Archives of Photogrammetry, Remote Sensing and Spatial Information Sciences 36 (Part 3/W19), 60-65.

Rack, K.J., Muller, J.P., Van Gasselt, S., Morley, J.G., Neukum, G, 2005. Automated Crater Detection, A New Tool for Mars Cartography and Chronology, Photogrammetric Engineering \& Remote Sensing. 71 (10), 1205-1217.

Relief Visualization Toolbox (RVT), 2015. http://iaps.zrc-sazu.si/node/67731\#v

Roussel, E., Toumazet, J.P., Florez, M., Vautier, F., Dousteyssier, B., 2014. Using airborne LiDAR in geoarchaeological contexts: Assessment of an automatic tool for the detection and the morphometric analysis of grazing archaeological structures (French Massif Central), European Geosciences Union, General Assembly 2014, Vienne (Austria) - 27 April - 2 May 2014.

Sauget, J.M., Fournier. G., Michelin, Y., Choplain, R., Maston, R., 2001. Paysages et architecture rurale entre Dômes, Sancy et Artense. Cantons de Rochefort Montagne, Tauves, La Tour d'Auvergne, ed. Association Etude du patrimoine auvergnat, Clermont-ferrand.

Schneider, A., Takla, M., Nicolay, A., Raab, A., Raab, T., 2014. A template-matching approach combining morphometric variables for automated mapping of charcoal kiln sites. Archaeological prospection. 22 (1), 45-62.

Sevara, C., Pregesbauer, M., Doneus, M., Verhoeven, G, Trinks, I., 2016. Pixel versus object -A comparison of strategies for the semi-automated mapping of archaeological features using airborne laser scanning data. Journal of Archaeological Science Reports. 5, 485-498.

Stark, M.T., Evans, D., Rachna, C., Piphal, H., Carter, A., 2015. Residential patterning at Angkor Wat. Antiquity, 89(348), $1439-1455$.

Stular, B., Kokalj, Z., Ostir, K., Nuninger, L., 2012. Visualization of Lidar-Derived Relief Models for Detection of Archaeological Features. Journal of Archaeological Science. 39, 3354-60

Tang, C.Y., Chen, Z., Hung, Y.P., 2000. Automatic detection and tracking of human heads using an active stereo vision system. International Journal of Pattern Recognition and Artificial Intelligence. 14, 137-166.

Toumazet, J.P., Vautier, F., Roussel, E., Flores, M., Dousteyssier, B. 2014., Automatic detection and characteristics extraction of archaeological structures using coupled Geographic Information System software and Scilab, In th International SCILAB users conference SCILABTEC, Paris.

Trier, Ø.D., Pilø, L.H., 2012. Automatic detection of pit structures in airborne laser scanning data. Archaeol. Prospect. 19 (2), $103-121$.

Trier, Ø.D., Zortea, M., Tonning, C., 2015, Automatic detection of mound structures in airborne laser scanning data. J. Archaeol. Sci. 2, 69-79.

Vosselman G., 2000. Slope based filtering of laser altimetry data. In Proceedings of the International Archives of Photogrammetry and Remote Sensing. 33, 935-942. 
Wan, C., Cheng, G.W., Zhou, Z., Zhao, S., Xia, Y., 2012. Automatic extraction of lunar impact craters from Chang'E-1 satellite photographs. Science China, Physics, Mechanics \& Astronomy. 55 (1). 162-169.

Zhang, K., Chen, S.C., Whitman, D., Shyu, M.L., Yan, J., Zhang, C., 2003. A progressive morphological filter for removing nonground measurements from airborne LiDAR data. IEEE Trans. Geosci. Remote Sens., 872-882.

Zakšek, K., Pfeifer, N., 2006. An improved morphological filter for selecting relief points from a LIDAR point cloud in steep areas with dense vegetation. Technical Report, Institute of Anthropological and Spatial Studies, Solvenia. http://iaps.zrcsazu.si/files/File/Publikacije/Zaksek_Pfeifer_ImprMF.pdf.

Zakšek K., Oštir K., Kokajl, Z. 2011. Sky-View Factor as a relief vizualisation technique. Remote sensing. 3, 398-415.

Zakšek, K., Oštir, K., Peter Pehani, P., Čota, K., Kokalj, Z., 2014. Relief Visualization Toolbox, version 1.1, Manual. Technical report. https://www.researchgate.net/publication/266632921_Relief_Visualization_Toolbox_version_13_Manual. 